\title{
La epigrafía funeraria y la idea de alma en Grecia Antigua (CEG 482; SEG 38: 440) ${ }^{1}$
}

\author{
Marta GonZÁlez GonZÁLez \\ Universidad de Málaga \\ martagzlez@uma.es
}

Recibido: $12-11-2013$

Aceptado: 8-01-2014

\section{RESUMEN}

Los epitafios privados son una interesante fuente de información para conocer las ideas de los antiguos griegos acerca del alma y su destino tras la muerte. El siglo iv a.C. constituye un punto de inflexión importante en este complejo asunto y, en la idea de que la perspectiva histórica es imprescindible en este tipo de estudios, reflexionamos en estas páginas sobre dos testimonios epigráficos de esta época, todavía poco estudiados, que nos muestran cómo en ese siglo IV a.C. no existe un pensamiento normativo ni se han convertido todavía en tópico las expresiones, comunes en época posterior, que aluden a la separación de alma y cuerpo.

Palabras clave: $p s y c h e ́$, inmortalidad, epigrafía griega, estelas funerarias.

\begin{abstract}
Private epitaphs are an interesting source of information to understand the ideas of the ancient Greeks on soul and its destiny after death. The fourth century B.C. is an important point of inflection on this complex subject. As the historical perspective is essential in this kind of studies, we reflect on these pages about two epigraphic texts from this period, so far overlooked, that show the ways in which in the fourth century BC there is no normative thought on this subject. Similarlily, expressions alluding to the separation of soul and body, frequent in later times, had not yet become cliché.
\end{abstract}

Keywords: psyché, Inmortality, Greek Epigraphy, Ancient Gravestones.

\section{SUMARIO}

1. Introducción. 2. El alma errante de Sosícrates. 3. Aristocles, brotado de la tierra. 4. Dioses sin alma, hombres mortales. 5. La inmortalidad astral y la doctrina materialista. 6. Epigrafía funeraria. Los diversos caminos de Sosícrates y Aristocles. 7. Conclusiones.

\section{SUMMARY}

1. Introduction. 2. Sosikrates' wandering soul. 3. Aristocles, sprung from the earth. 4. Gods soulles, mortal men. 5. Astral inmortality and materialistic theory. 6. Funerary Epigraphy. Sosikrates and Aristocles, different paths. 7. Conclusions.

${ }^{1}$ Este trabajo se adscribe al Proyecto de Investigación HAR 2011-27092. 
La alusión a una muerte inicua junto al hecho de que el alma vague errante nos hace recordar una idea bien conocida y que podemos reproducir en términos tomados de Erwin Rohde: «En la Atenas de los siglos v y IV manteníase todavía en pleno vigor la creencia de que el alma de una persona muerta por la violencia vagaba sin encontrar sosiego mientras no se vengase el crimen en el asesino» ${ }^{6}$. Sin embargo, como siempre nos ocurre con los testimonios epigráficos, las escasas líneas que los componen son todo lo que hay y no nos conceden opciones de llegar a saber nada más, ningún otro detalle - salvo en el caso de que se conserve la estela - que satisfaga la curiosidad despertada. Podemos, a cambio, profundizar un poco más en el sentido de los términos empleados en el epitafio: öøıৎ forma parte del lenguaje religioso y su significado se entiende en relación y por oposisión a ícós, de manera que hierós es lo sagrado y hósios señala, en referencia a un hombre y su comportamiento, que éste es conforme al orden religioso. Sin embargo, negados, ambos términos son equivalentes, tanto el aníeros como el anósios atraen la cólera de los dioses y el asesino es el anósios por excelencia: «Le meurtrier est l' anósios type, tandis que celui qui tue selon la justice, à la guerre ou en fonction du jugement rendue par un tribunal, est hósios» ${ }^{7}$. También

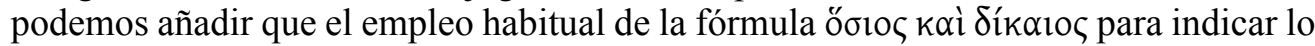
que les está permitido a los hombres por parte de los dioses ${ }^{8}$, añade un valor mayor en este epitafio a la negación de ambos términos en relación con la muerte de Sosícrates:

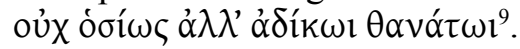

No podremos, obviamente, confirmar que Sosícrates fue asesinado ${ }^{10}$, pero sí asegurar que si se dice que murió de manera impía con muerte inicua en un epitafio del siglo IV a.C, cuando no era ni muchísimo menos común dar detalles sobre el tipo de muerte sufrida, cuando incluso parece que había una norma no escrita que lo vetaba ${ }^{11}$, es que estamos ante unas circunstancias excepcionales que quien elevó

${ }^{6}$ Rohde (1948: 122). También Bremmer (2002: 77), aunque muy de pasada, se refiere a la creencia de que las almas de algunos muertos, en concreto, los muertos prematuros o los muertos de muerte violenta, tenían un destino diferente a las de los demás. Muy interesante en relación con este asunto es el estudio de Johnston (1999), que dedica un capítulo a los biaiothanatoi: «Dealing with Those Who Die Violently».

${ }^{7}$ Burkert (2011: 359). Cito por la edición francesa, realizada teniendo en cuenta la segunda alemana de 2011. En el mismo sentido, véase Rudhardt (1992: 34): «Fait très remarquable, ce n'est pas la mort violente en elle-même qui constitue l' óvóøıov: le meurtre légitime compensant une irrégularité ou visant

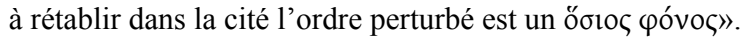

${ }^{8}$ Chantraine $\left(2009,1968^{1}\right.$ : s.v. öøloৎ).

${ }^{9}$ Menciona este epitafio Bremmer (1994: 3-4), que comenta el valor de hósios: «Another key term in this area is hosios. It had a wide range with a basic meaning of "permitted by or pleasing to the gods". For example, hosios could be contrasted with hieros in order to constrast civic funds with those of the gods, but could also denote purity because pollution is offensive to the gods. More strongly, the notion of "pleasing" included that of "justice", as is illustrated by a recently published funerary epigram of a certain Sosikrates, who died "not in a hosios way but through an unjust death"».

${ }^{10} \mathrm{Cf}$. el siguiente epigrama en el que se emplea la expresión oủx óoí $\omega \varsigma$ para referirse a la muerte, a

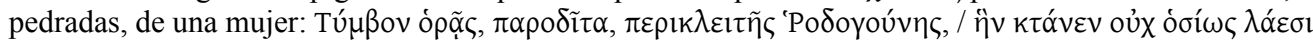

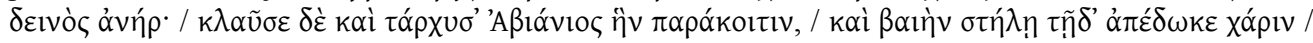

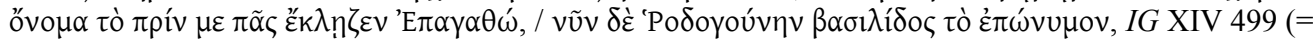
GVI 1936, SEG 19.608), epitafio procedente de Catania y de fecha incierta, ca. s. II-III d.C.

${ }^{11}$ Las circunstancias de la muerte no se indican en los epitafios funerarios de época arcaica y clásica. Existen tres excepciones: muerte en la guerra, muerte en el mar, muerte en el parto; el caso que aquí pare- 
el memorial en su honor no quiso dejar de, al menos, aludir ${ }^{12}$. Igualmente original, y pienso que probablemente relacionada con esa muerte criminal, es la referencia al destino del alma de Sosícrates, que mezclada con el etéreo cielo anda errante. En ningún otro epitafio, de los publicados hasta ahora, encontramos una expresión igual ni similar ${ }^{13}$.

Otro epigrama fúnebre, también de Tesalia pero de muy diferente tenor y de época helenística, es el de Licofrón. Lo recuerdo ahora porque también menciona el diferente destino del cuerpo y el alma así como el viaje de ésta al éter; se trata del siguiente texto, más conocido y estudiado:

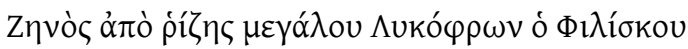

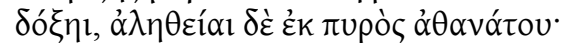

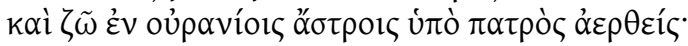

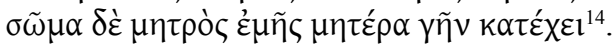 \\ De la raiz del gran Zeus, soy Licofrón, hijo de Filisco \\ en apariencia, pero, en realidad, del fuego inmortal. \\ Vivo entre los astros celestes llevado al éter por mi padre. \\ El cuerpo, en cambio, nacido de mi madre, ocupa la tierra madre.
}

El difunto Licofrón vive «entre los astros celestes», mientras que su cuerpo ocupa

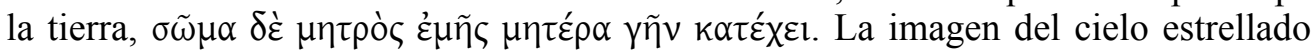
como patria divina ha sido entendida como eco órfico, pitagórico, o en relación con la tradición literaria que vincula la inmortalidad astral con Tesalia, tierra de magos ${ }^{15}$. Además, hay una referencia explícita a la inmortalidad, aunque sea la del fuego. Pero

ce sugerido, una muerte injusta, quizá un asesinato, será un detalle que sí formará parte del repertorio de la epigrafía helenística y de la literatura epigramática de la misma época, pero que no se conocía en época anterior.

${ }^{12}$ Tan poco habitual es la expresión oủx ó $\sigma i ́ \omega \varsigma$, que sólo aparece en otro epigrama funerario, también del siglo iv a.C. El texto es en este caso muy fragmentario y sólo se conserva el comienzo de cada uno de los cuatro hexámetros que lo componen; en el cuarto se lee oủx óoí $\omega[\varsigma$. CEG 497 (= GVI 541), Ática, encontrado en el Cerámico. Museo Epigráfico n. 9474. Es importante insistir en la originalidad de esta expresión, ya que suele existir el prejuicio de que la epigrafía funeraria es repetitiva y excesivamente convencional, algo que, si acaso, sería cierto sólo más adelante, pero en absoluto en la epigrafía funeraria métrica arcaica y clásica.

${ }^{13}$ Sólo en dos pasajes, los dos de Plutarco, he visto el verbo $\pi \lambda \alpha v \alpha \tilde{\alpha} \alpha$ l dicho del alma: De curiositate

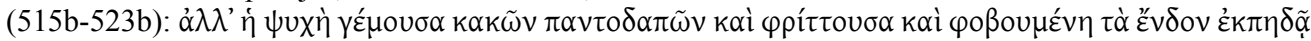

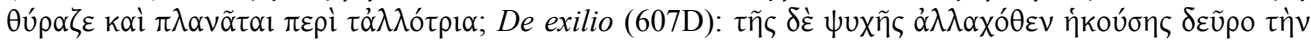

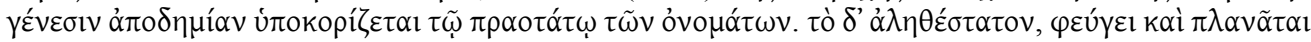

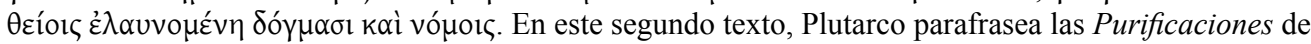
Empédocles.

${ }^{14}$ SEG 28: 528 (1978), s. III a.C., hallado en Feras, Tesalia, Museo de Volos, E 1238. También está recogido y estudiado en Cairon (2009, número 77).

${ }^{15}$ Cairon (2009: 244): «La mention de l'immortalité astrale dans un épigramme thessalienne rappelle la tradition littéraire qui fait de la Thessalie la terre d'élection des mages et de la magie. Le pouvoir des astres et sur les astres est une part importante de la croyance des mages. De plus, des nombreuses monnaies ont été trouvées avec des figurations astrales». $C f$. también Avagianou (2002) y Jiménez (2011: 74): «La creencia en la naturaleza dual del hombre y la inmortalidad del alma coinciden con doctrinas 
estamos ya en el siglo III a.C. y la alusión a los astros celestes como morada del alma, entendida en el sentido que sea, no resulta tan llamativa como el alma errante mezclada con el etéreo cielo del epitafio de Sosícrates.

\section{ARISTOCLES, BROTADO DE LA TIERRA}

Consideremos ahora una estela de mármol pentélico procedente de la colección de lord Elgin, el memorial de Aristocles, del siglo IV a.C. como el de Sosícrates, aunque esta vez del Ática. En ella aparece representado el difunto como un varón con barba y a caballo acompañado por un asistente. La inscripción la componen tres versos:

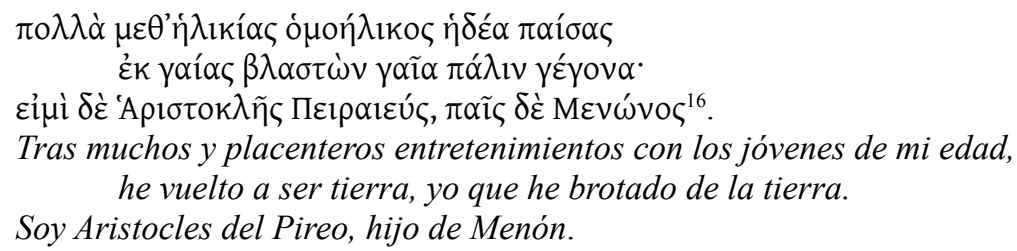

Aristocles afirma en primera persona que él se vuelve tierra: «la peculiaridad del motivo del volverse tierra impide considerar como algo puramente casual el silencio sobre una forma de supervivencia, del tipo que sea, del individuo tras la muerte», se señala en un interesante artículo dedicado a este epitafio por Maria Michela Sassi ${ }^{17}$. La autora añade que, frente a afloramientos discontinuos de tendencias escatológicas, lo que esta inscripción funeraria deja ver es una orientación conservadora, una permanencia de los valores aristocráticos en la Grecia de los siglos v y IV a.C., afirmación que tiene un apoyo en las siguientes palabras de Guthrie: «la fuerza física y la vitalidad parecían cosas tan gloriosas que, incluso si el alma continuaba existiendo, su separación del cuerpo tenía que significar que éste había perdido todo aquello por lo que valía la pena vivir ${ }^{18}$. Aristocles — buen nombre para un aristócrata-, tras haber compartido con sus iguales los goces de la vida, se vuelve tierra y a la tierra de la que ha nacido.

Ciertamente, la fórmula llama la atención, ya que no se trata de que la tierra lo aco-

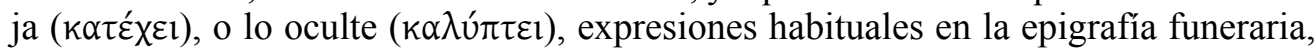
sino de algo más radical: el difunto se vuelve tierra. Aunque representando, parece, una línea de pensamiento opuesta a la que inspiró el memorial de Sosícrates, lo cierto es que con él comparte el hecho de dar cabida en un epitafio privado a reflexiones escatológicas en un momento tan temprano como los inicios del siglo iv a.C.

atribuidas a los órficos, cuya presencia en Feras corrobora el hallazgo de dos laminillas áureas datadas en los siglos IV-III a.C.».

${ }^{16} C E G 482$ (= GVI 1702), inicios del s. Iv a.C., Ática. Museo Británico de Londres, n. 1816 6-10-184.

${ }^{17}$ Sassi (1981: 34). La autora documenta y analiza los textos filosóficos y literarios que muestran afinidades con esta idea de «volverse tierra».

${ }^{18}$ Sassi (1981: 36), citando a Guthrie (1950: 280). 
Otro ejemplo de «brotado de la tierra», pero parece que de muy distinto tenor, es el siguiente, un epigrama del s. III a.C., de Eretria:

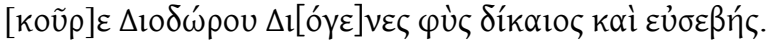

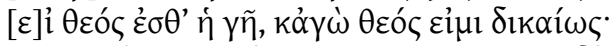

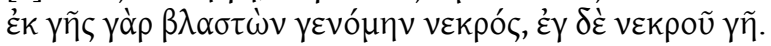

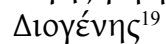
Diógenes, hijo de Diodoro, por naturaleza justo y piadoso.
Si la tierra es un dios, también yo, en justicia, soy un dios:
brotado de la tierra me he convertido en cadáver y, de cadáver, tierra.
Diógenes

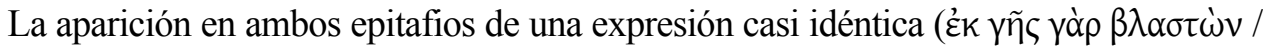

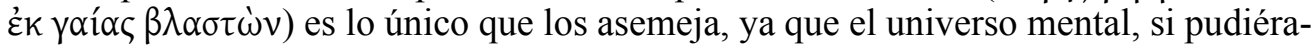
mos emplear esta expresión, de uno y otro memoriales es diametralmente opuesto. Se

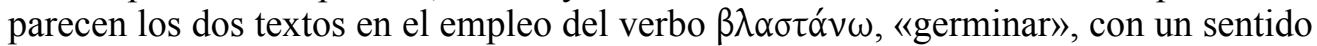
vegetal que admite el uso metafórico que aquí vemos y del que Eurípides ofrece un buen número de ejemplos ${ }^{20}$; es decir, los dos epigramas relatan de igual modo el nacimiento de sus protagonistas, pero difieren en su destino final. En el segundo se percibe un interés escatológico extraño: el muerto se autoproclama hijo de la tierra, se le invoca como piadoso, pero el epitafio no puede asimilarse a los textos órficos habituales que presentan a los iniciados como hijos de la Tierra y del Cielo Estrellado ${ }^{21}$; en el de Aristocles, que es el que ahora nos intersa por ser del siglo iv a.C., la perspectiva escatológica está sólo sugerida y parece asumirse que la muerte es el fin de la historia.

Vistos los epigramas funerarios de Sosícrates y Aristocles, consideremos ahora el contexto en el que aparecen, precisamente eso que hace que los veamos como ejemplos de interés excepcional.

\section{DIOSES SIN ALMA, HOMBRES MORTALES}

La consideración del alma como figura central del pensamiento religioso y moral fue una novedad, por largo tiempo marginal, introducida en Grecia en torno al s. vi a.C. por movimientos dionisíacos, órficos y pitagóricos ${ }^{22}$. Parto de una consideración casi banal: los hombres son mortales y los dioses inmortales. Esta idea - homérica diríamos, para entendernos - es la que predomina en la mentalidad griega arcaica y en gran parte de la clásica. Es significativo, pero en absoluto extraño, que en el estudio de Walter Burkert sobre la religión griega la primera alusión a la inmortalidad del alma se encuentre casi en las últimas páginas. Cita el historiador de la religión el famoso

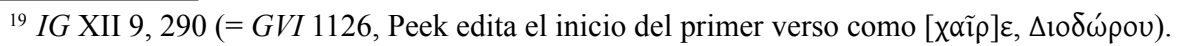

${ }^{20}$ De nuevo nos encontramos con el poeta Eurípides como posible inspirador del lenguaje literario de los epigramas. Para el uso de $\beta \lambda \alpha \sigma \tau \alpha ́ v \omega$ y derivados, cf. Andr. 664, HF 4 y 178, Ion 267.

${ }^{21}$ Betz (2010: 106) menciona este epitafio, pero sólo para referirse a él como «strange».

${ }^{22}$ Vegetti (1989: 75 ss.). No debemos desdeñar tampoco el papel desempeñado por Heráclito en la reflexión sobre la $\psi v x \eta ́$, brillantemente analizado por Nussbaum en dos artículos, (1972a, 1972b).
} 
y discutido pasaje de Heródoto en el que se hace mención de órficos y pitagóricos ${ }^{23}$, mención con la que se reenvía a Orfeo y Pitágoras, «dos figuras que, por oposición a la religión griega, difusa pero siempre tradicional, asumen por primera vez el papel de fundadores de una secta, si no de una religión. De manera significativa, el primero se presenta como un bardo y un poeta y el segundo como un "filósofo". La transformación más profunda de la religión griega tiene que ver con estos dos nombres. Los términos "alma" e "inmortalidad" son sus piedras de toque» ${ }^{24}$.

Aunque esta idea parece clara, no está de más insistir en ella, teniendo en cuenta que muchas veces, hablando del alma, se identifica su separación del cuerpo y su gris y parcial supervivencia con la inmortalidad. El alma que se escapa con el último aliento o a través de las heridas del guerrero agonizante en la llanura troyana, sobrevive —no sabemos por cuánto tiempo, sí sabemos en qué tristes condiciones- pero no es inmortal. Sólo los dioses lo son, ¿quizá, precisamente, porque ellos no tienen alma? La reflexión acerca de la ausencia de $\psi v x$ ń en los Inmortales, que tomo de Nussbaum ${ }^{25}$, el hecho de que ningún poeta haya hablado del alma de ninguna divinidad, la entiendo en relación con la constante que en el pensamiento griego separa a los dioses de los hombres, considero que tiene el mismo valor simbólico, por ejemplo, que referirse a los hombres como «comedores de pan», con todas las implicaciones que de ello se desprenden y que dejó perfectamente claras Jean-Pierre Vernant en su análisis del mito prometeico desvelando la relación entre la inmortalidad divina y la no dependencia del alimento $^{26}$.

Así pues, la mera posesión de una $\psi v x \eta ́$ implica la condición mortal del hombre $\mathrm{y}$, además, que en el momento de la muerte alma y cuerpo se separen no supone la inmortalidad de la primera. Los pitagóricos sí creyeron que el alma era inmortal y esa creencia rompía con lo que podríamos llamar religión homérica, que era ciertamente insuficiente para el griego común de los siglos siguientes, pero que, si no plenamente en el fondo, sí en la forma, dejó enorme huella en la literatura griega hasta época muy avanzada.

Otras ideas se abrían paso muy poco a poco y comenzaban a formar parte tanto de creencias de tipo popular como de sistemas filosóficos más elaborados. Ya lo señaló Guthrie, describiendo de manera clara la confluencia en la filosofía presocrática de dos tradiciones de origen diverso:

Reconocer la existencia e interacción de las dos grandes corrientes de tradición filosófica, la jonia y la itálica, es de primera importancia para una comprensión de la filosofía presocrática; pero es igualmente importante ser conscientes de que representan,

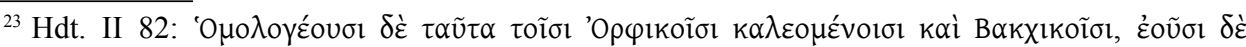

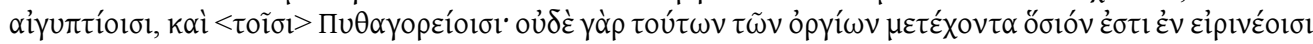

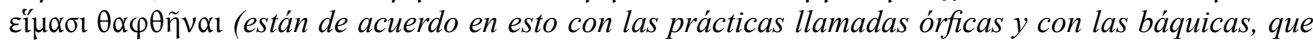
son en realidad egipcias, y pitagóricas, pues tampoco está permitido que ninguno de los que participa en estos misterios sea enterrado con ropas de lana).

${ }^{24}$ Burkert (2011: 390).

${ }^{25}$ Nussbaum (1972a: 2). La autora analiza también y explica convincentemente los escasísimos pasajes en los que se atribuye un alma a alguna divinidad.

${ }^{26}$ Vernant (1974). 
en sus respectivas esferas, algo amplio, las dos tendencias opuestas en el espíritu griego, cuyo conflicto e interrelación forman un aspecto esencial y fascinante del estudio de la vida griega y de su literatura en general. Estas dos tensiones, a su vez, hallan su explicación, en parte, en la fusión de razas que llegaron a formar parte del pueblo griego en los tiempos históricos [...] Puede resumirse en las palabras $\theta v \eta \tau \grave{\alpha} \varphi \rho o v \varepsilon \tilde{v} v$ («pensar

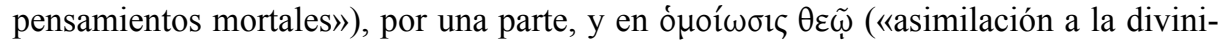
dad») por la otra ${ }^{27}$.

En los presocráticos conviven, inseparables, las dos tendencias $\mathrm{y}$, como hemos visto, también en los epitafios funerarios hay rastros, aunque escasos y dispersos, de esas mismas tradiciones diversas.

\section{LA INMORTALIDAD ASTRAL Y LA DOCTRINA MATERIALISTA}

Con el epitafio público por los caídos en la batalla de Potidea del 432 a.C., siempre invocado al hablar de la consideración del alma en la epigrafía funeraria como primer testimonio con el que podemos contar sobre este asunto, no abandonamos a William K.C. Guthrie, que ya lo señaló como excepcional para el siglo v a.C. En ese epigrama

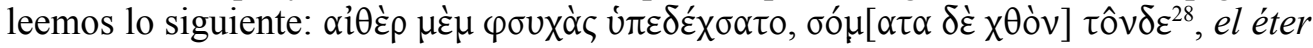
acogió sus almas, la tierra sus cuerpos. Lo que Guthrie entendió como más relevante en este caso es que encontramos una afirmación como ésta, «no en un filósofo, o en un poeta como Eurípides, sino en una inscripción grabada en piedra para que todos la vieran y, supuestamente, la apreciaran». Incluso, continúa Guthrie, aceptando, como parece claro, que estas inscripciones fueran obra de grandes poetas, su propósito debía ser que todos entendieran su mensaje ${ }^{29}$. Este mismo epitafio, en opinión quizá demasiado aventurada de algunos estudiosos, sugiere también ya la idea de que la psyché o pneûma sube al cielo después de la muerte, esa imagen de una «estancia celeste» que se va difundiendo lentamente en Grecia a partir de la mitad del siglo v a.C. ${ }^{30}$ y que está muy próxima a la creencia de que las almas que vuelan hacia el éter se convierten, de hecho, en estrellas. Se trataría, en definitiva, de lo que se conoce como «inmortalidad celeste», basada en la noción de un éter divino al que vuelve el alma, elemento divino del hombre, tras la muerte, idea sostenida simultáneamente por la fe popular y por la

${ }^{27}$ Guthrie (1984: 194 ss.).

${ }^{28}$ CEG 10.6 (= GVI 20).

${ }^{29}$ Guthrie (1950: 262).

${ }^{30}$ Burkert (2002: 136ss.) entiende que puede tratarse de una evolución independiente del pensamiento griego (el concepto de $\alpha i \theta n ́ p$, el retorno a los orígenes) y que no es necesario presuponer influencia oriental. Sobre el viaje del alma al aither, tomando como punto de partida el epitafio de Potidea, hay un detallado estudio, con comentario de las fuentes filosóficas, en Mihai (2010). En este artículo puede leerse la siguiente conclusión, en clara polémica con la concepción dualística del alma, difundida sobre todo por Bremmer para el ámbito griego, Mihai (2010: 577): «What the Greek testimonies on the journey of the soul confirm, notwithstanding their reinterpretation by modern scholarship, is that during the two centuries preceding Plato, the psuchê was represented as leaving the body and wandering on Earth or in the sky, that is, in the aither». 
doctrina materialista del siglo v a.C. ${ }^{31}$ Habré de volver más adelante a ese epitafio de los caídos en Potidea.

Pero los primeros testimonios aducidos sobre este germen de una cierta idea de inmortalidad no son epigráficos, sino de poetas como Epicarmo, autor cómico al que la tradición antigua asociaba a los pitagóricos. Así leemos en uno de sus fragmentos:

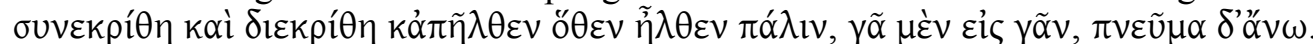

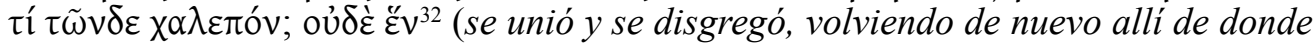
habia venido, la tierra a la tierra, el aliento arriba. ¿Qué hay de extraño en eso? Nada).

En la segunda mitad del s. v a.C. es sobre todo Eurípides quien difunde la idea,

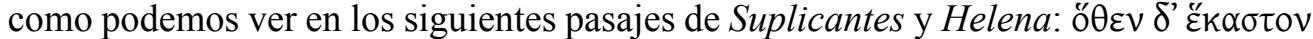

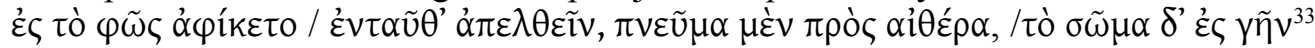
(de donde cada cosa llegó a la luz / allí vuelve, el aire al éter, / el cuerpo a la tierra); ó

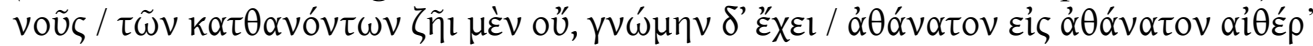
$\varepsilon \mu \pi \varepsilon \sigma \omega v^{34}$ (la mente / de los que han muerto ya no vive, pero mantiene la conciencia / inmortal al caer en el inmortal éter). Además de estos dos pasajes, tiene especial importancia un fragmento de Crisipo en el que se lee: $\chi \omega \rho \varepsilon \tilde{\imath} \delta$ ỏ $\pi i^{\prime} \sigma \omega / \tau \dot{\alpha} \mu \grave{\varepsilon} v \dot{\varepsilon} k$

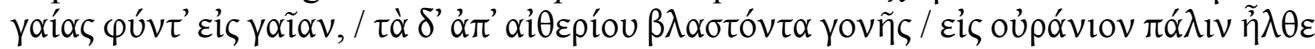
$\pi{ }^{\prime}{ }{ }^{35}{ }^{35}$ (vuelve atrás / lo nacido de la tierra a la tierra/ y lo engendrado de la semilla del éter / de nuevo al círculo celeste), versos en los que se ha señalado el reflejo de las ideas de Anaxágoras ${ }^{36}$.

Estas ideas sobre una inmortalidad del alma asociada a su naturaleza celeste, tal como se encuentran expresadas en Epicarmo, Alcmeón, Parménides o Anaxímenes,

${ }^{31}$ Guthrie (1950: 264) «When I spoke in an earlier chapter of the airy or aetherial nature of the soul as a being doctrine of the materialistic science of the fifth century, I pointed out that it only meant the reappearance in rational dress of an age-old popular belief. When science and primitive belief are thus united in their conclusions, it would obviously be difficult to say which was responsible for the prevalence of a specific idea at this advanced stage of civilization. I think myself that if this particular idea was widespread in the fifth century, as perhaps the Potidaea epitaph shows, then its diffusion is most likely to have been due to the influence of popular science».

${ }^{32}$ Epich. Fr. 213 K.-A.

${ }^{33}$ E. Supp. 532-4.

${ }^{34}$ E. Helena, 1014-1016.

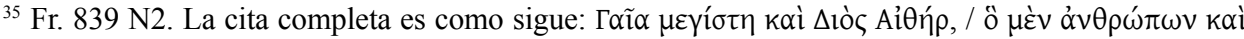

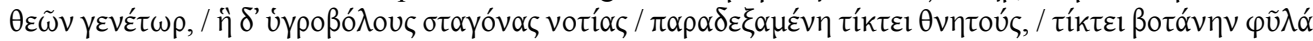

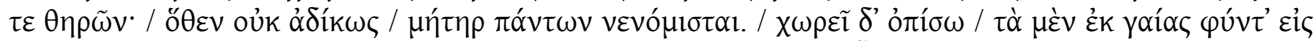

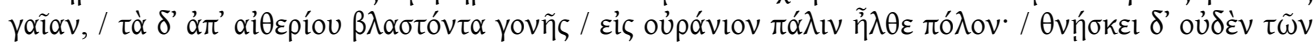

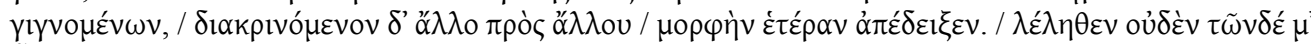

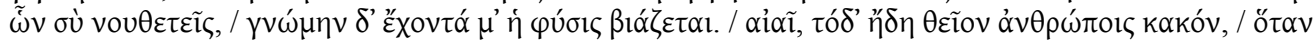

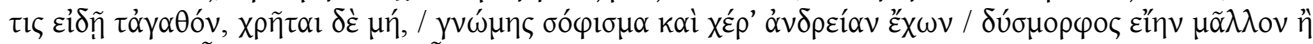

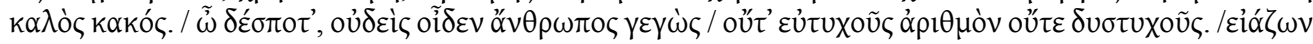

${ }^{36}$ Estos pasajes, tanto el de Epicarmo como los de Eurípides, además de otros fragmentos del poeta trágico en los que reaparece el tema del alma y el éter inmortal, son analizados detalladamente en Egli (2003: 94-114). Entiende la autora que la creencia que está en la base de estas consideraciones es que el éter es un elemento divino y que, de modo natural, la parte divina del hombre vuelve, tras la muerte, a ese elemento. Como ejemplos de esa misma idea aduce los epitafios de Eurímaco y Sosícrates aquí comentados. 
fueron adscritas a Pitágoras por Jámblico, Máximo de Tiro o Hipólito y encontraron gran eco en Platón ${ }^{37}$.

Junto a esta crencia, contamos con una corriente distinta, la que testimonia, por

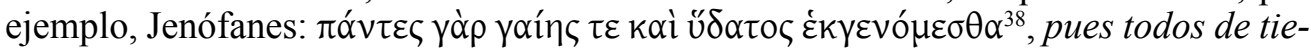
rra y agua hemos sido hechos, idea que también en este caso hunde sus raíces en una tradición anterior poética igualmente extensa ( $\mathrm{vg}$. el mito hesiódico de Pandora). Se

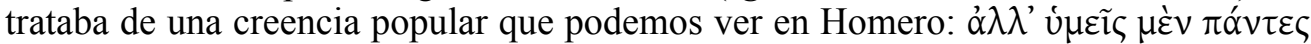

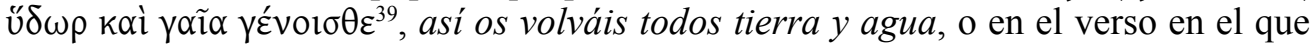
se refiere al cadáver de Héctor al que Aquiles ultraja como $\kappa \omega \varphi \eta ̀ v . . . ~ \gamma \alpha \tilde{a} \alpha v^{40}$, tierra sin voz. Sin embargo, parece que en el siglo v a.C. estas ideas ya no tenían una gran difusión, por lo que reviste una especial importancia su aparición en el epitafio de Aristocles que he considerado más arriba.

\section{EPIGRAFÍA FUNERARIA. LOS DIVERSOS CAMINOS DE SOSÍCRATES Y ARISTOCLES}

En los epigramas funerarios, partiendo de la idea que expresaba al principio, de la necesidad de una perspectiva histórica, no puede afirmarse que la referencia a la separación del cuerpo y el alma sea en ellos una standar expression ${ }^{41}$; ni muchísimo menos. Sólo dejará de ser extraña en época helenística. En concreto, en relación con el epitafio de los guerreros caídos en Potidea, lo que se puede señalar con bastante seguridad es que su referencia al éter que acoge las almas de los fallecidos es excepcional para el siglo v a.C. y que no implica la inmortalidad de la $\psi u x \eta ́$ : sólo considera, probablemente desde una perspectiva física, la imagen del último aliento.

Escasos y ya de mediados del siglo IV a.C. son los testimonios epigráficos que mencionan la separación de alma y cuerpo a la hora de la muerte:

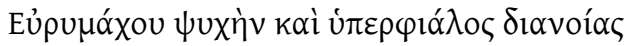

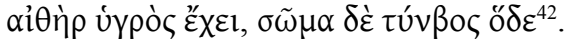

\footnotetext{
${ }^{37}$ Avagianou (2002: 83).

${ }^{38}$ Fr. 33.

${ }^{39} \mathrm{Il}$. VII 99.

${ }^{40} \mathrm{Il}$. XXIV54.
}

${ }^{41}$ Lo afirman, entre otros autores, Avagianou (2002: 75): «The main idea of the epigram, that the soul of the dead goes to astral heaven while the body returns to the earth, that is, the mother, is easy to grasp and it could be argued that this notion is a standar expression in funerary epigrams» y (2002: 80): «The opposition between the place of body's rest — earth, tomb — and that of the soul — sky, stars, Isles of Blessed, the Elysian Fields - is a recurring motif in funerary epigrams». También Jiménez (2011: 73): «La idea de que tras la muerte cuerpo y alma se separan y cada uno regresa a su lugar de origen - el cuerpo a la tierra, el alma al éter- es un motivo recurrente en epigramas literarios y epigráficos». A veces, se cita como referencia el estudio de Le Bris (2001) que, sin embargo, y como el propio subtítulo del libro indica, se centra en las épocas helenística y romana.

${ }^{42}$ CEG 535 (= GVI 1755), ca. 350 a.C. Estela de mármol encontrada en el Pireo, ahora en el Mus. Forensi I 1114. 


\section{El alma de Eurímaco y sus grandes pensamientos los tiene el húmedo éter; su cuerpo, esta tumba.

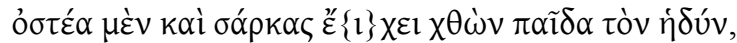

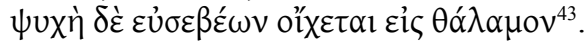 \\ La tierra tiene los huesos y la carne, al dulce niño, y su alma ha partido hacia el lecho de los piadosos}

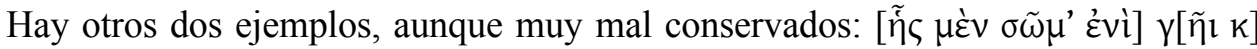

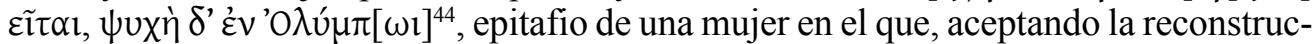

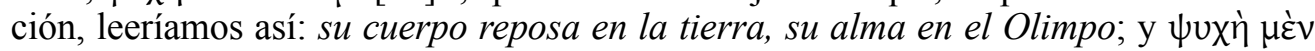

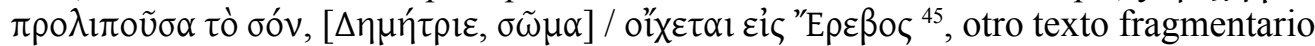
en el que quizá se lea lo siguiente: Tras abandonar el alma tu cuerpo, Demetrio, parte hacia el Érebo. De todos ellos, sólo en el primero se habla del éter como destino de las almas; en el resto, simplemente se alude a que sigue un camino diferente al del cuerpo tras la muerte y, por supuesto, no se menciona la inmortalidad, ni del alma ni del éter.

Pero, incluso con aquellos epitafios más explícitos, como el de los caídos en Potidea, hay que ser cuidadosos a la hora de extraer conclusiones. En un estudio que está ya a punto de cumplir los cien años, Lewis R. Farnell se mostraba mucho más precavido que algunos modernos estudiosos que consideran este texto un ejemplo temprano de «inmortalidad astral» ${ }^{46}$, y creo que la razón estaba de su lado. Las inscripciones sepulcrales, a las que el autor concedía gran importancia como testimonios poco sospechosos de insinceridad o hipocresía - cada quien pensaba lo que quería, si es que pensaba algo, acerca del Más Allá - demuestran, dice, hasta pasada la mitad del siglo v a.C., poco interés por el tema del destino póstumo. Por lo que se refiere, en concreto, al famoso epitafio que tantas veces he mencionado, esto es lo que Farnell afirma:

Que el alma que acaba de escapar se eleve y vuele hacia el éter, era probablemente una antigua creencia popular [...] Pero debemos tener dudas sobre si el epitafio público de Potidea tiene algún valor religioso escatológico; puede que sólo haya expresado la percepción casi física de que el alma, como el aliento, escapa hacia el aire: por ejemplo, otro epitafio ático del siglo IV a.C. declara que «el húmedo éter ha absorbido el alma y

${ }^{43}$ CEG 545.1-2 (= GVI 1757), ca. 350 a.C. Estela de mármol encontrada en un lugar desconocido de Atenas, ahora en el Museo Epigráfico, n. 8842.

${ }^{44}$ CEG 558.2 (= GVI 595), ca. 350 a.C. Fragmento de una base de mármol encontrada en el Odeón de Herodes, ahora en el Museo Epigráfico, n. 9475. La reconstrucción de la que depende que este epitafio constituya un ejemplo más por lo que a la aparición de $\sigma \tilde{\omega} \mu \alpha$ se refiere, es de Kaibel. Hansen no la acepta en su totalidad, pero sí en lo que se refiere a ese término.

${ }^{45}$ CEG 548.2-3 (= GVI 1963), ca. 350 a.C. Estela de mármol encontrada en lugar desconocido, ahora en el Museo Nacional de Atenas, n. 1115. De nuevo se trata de una reconstrucción en el caso del término $\sigma \tilde{\omega} \mu \alpha$.

${ }^{46}$ Sourvinou-Inwood (1995: 194): «In the epitaph for the Athenians fallen in the battle of Poteidaia the dead are associated with yet another type of immortality, celestial immortality, a concept which originated in philosophical thought». 
los poderosos pensamientos» de alguien que se ha ido y la frase sugiere una concepción más física que espiritual.

Farnell mencionaba también, como vemos al final de esta cita, uno de los epitafios que he recogido más arriba. Añadía este autor, en fin, que todavía en los siglos IV y III a.C. continuaban siendo pocos los epitafios en los que se expresaban «ardientes deseos o positivas convicciones» sobre el Más Alláa ${ }^{47}$. Esta afirmación de Farnell se ve confirmada en la reciente edición de los epigramas funerarios de época helenística de Élodie Cairon ${ }^{48}$, en donde sólo vemos mencionado el éter en dos casos, uno de ellos muy tardío, del siglo I a.C.49; el otro, más temprano, del siglo III a.C. y de Atenas, está dedicado a un niño de siete años:

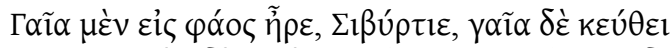

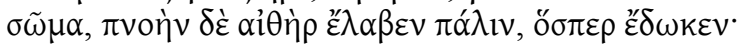

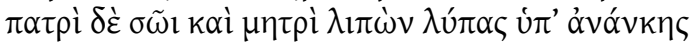

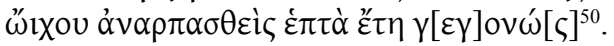

La tierra te trajo a la luz, Siburtio, y la tierra esconde tu cuerpo; tu aliento lo ha recuperado el éter, el mismo que te lo había dado: dejando dolor a tu padre y a tu madre, por la necesidad arrebatado, te has ido a los siete años.

Estos pocos ejemplos dejan ver la lentitud con la que se introduce en el repertorio de las expresiones epigráficas la idea de que el alma vuelve al éter tras la muerte ${ }^{51}$, incluso en formulaciones desprovistas de connotaciones religiosas: no se dice del alma que sea inmortal, ni que lo sea el éter, algo que sí se afirmaba explícitamente en los pasajes de Eurípides citados al comienzo de este trabajo.

\section{CONCLUSIONES}

Cuando Burkert habla de orfismo, dionisismo y pitagorismo, nos propone una imagen muy clara, la de tres círculos que se intersecan. Orfismo y dionisismo se encuen-

${ }^{47}$ Farnell (1921). Las consideraciones sobre las inscripciones funerarias ocupan las últimas páginas del estudio, 397-401. De la misma opinión que Farnell en cuanto al epitafio de Potidea es Le Bris (2001: 82): «Il est néanmoins douteux qu'il y ait derrière cette formulation une idée eschatologique; elle correspond plus probablement à un simple concept physique. En réalité, cette croyance ne se répand vraiment qu'à partir de l'epoque hellénistique».

${ }^{48}$ Cairon (2009, número 14).

${ }^{49}$ Cairon (2009, número 93).

${ }^{50}$ Cairon (2009, número 20).

${ }^{51}$ Vérilhac (1978), cuyo estudio de los epitafios de niños abarca un extensísimo espectro temporal, es muy cuidadosa para no caer en generalizaciones. Esto es lo que afirma sobre el éter como residencia de las almas, pág. 294 vol. II: «La croyance au séjour de l'âme dans l'éther ne semble pas avoir été très répandue avant l'apparition du stoïcisme. L'épitaphe pour les guerrieres de Potidée est seule dans la poésie funéraire à en transmettre l'écho, et les témoignages littéraires sont eux aussi très rares. Les nombreuses épigrammes non stoïciennes qui présentent l'âme comme un souffle sont postérieures à l'époque classique». 
tran en la atención al Más Allá y al mito de Dioniso; orfismo y pitagorismo, en la doctrina de la metempsícosis y en el ascetismo; los tres en la transformación radical del concepto de $\psi v \times y^{52}$. Si atendemos a los testimonios de la epigrafía funeraria privada, a lo que el hombre común podía creer sobre la cuestión del alma, la información segura que de ella podemos extraer es poca: hasta el siglo III a.C. las preocupaciones escatológicas están prácticamente ausentes de este corpus y los escasos testimonios con los que contamos no permiten adscripciones claras a una u otra corriente de pensamiento. Debido a que, como ya he recordado, ideas como que el cuerpo es tierra y el alma-aliento es aire formaban parte de las creencias populares al mismo tiempo que de las elaboraciones filosóficas, no sería extraño que tuviéramos que reservar un cuarto círculo, para continuar con la imagen de Burkert, para aquellos que, diríamos, oían campanas pero no sabían dónde. O para decirlo con términos más académicos, para aquellos simples mortales cuyos epitafios suelen ser dejados de lado en las grandes teorías o confinados a notas a pie de página con la etiqueta de «extraño».

La epigrafía funeraria, como corpus abierto, por fortuna en continuo crecimiento, nos ha conservado los nombres de Sosícrates, cuya alma sigue vagando por el éter, y de un resignado Aristocles, en otro tiempo feliz, que parece aceptar que hasta aqui hemos llegado. El interés de estos epigramas está en que, aunque sea en una pequeña medida, ambos constatan, en la primera mitad del siglo IV a.C., una cierta inquietud escatológica por parte de simples particulares, difícilmente reductible a una determinada corriente de pensamiento religioso o filosófico. Es tentador, pero imposible sin caer en una simplificación, considerar estos dos personajes, de Tesalia y Ática respectivamente, como paradigmas de la tierra de los magos en un caso y de los orgullosos autóctonos en el otro.

\section{BIBLIOGRAFÍA}

Avagianou, Aphrodite A. (2002), «Physiology and Mysticism at Pherai. The Funerary Epigram for Lykophron», Kernos 15: 75-89.

Betz, Hans Dieter (2010), "“A child of Earth am I and of starry Heaven” Concerning the anthropology of the Orphic gold tablets», en Radcliffe G. Edmonds III, (ed.), The "Orphic» Gold Tablets and Greek Religion: Further Along the Path, Cambridge: 102-119.

Bremmer, Jan N. (1994), Greek Religion. Cambridge.

- (2002), El concepto del alma en la antigua Grecia, trad. cast. Madrid.

Burkert, Walter (2002), De Homero a los Magos, trad. cast. Barcelona.

- (2011), La religion grecque à l'époque archaïque et classique, trad. fr. París.

CAIron, Élodie (2009), Les épitaphes métriques hellénistiques du Péloponnèse à la Thessalie. Budapest.

Chantraine, Pierre (2009, 1968¹), Dictionnaire étymologique de la langue grecque. Histoire des mots. París.

${ }^{52}$ Burkert (2011: 396). 
Di Tillio, Zopito (1969), «Confronti formulari e lessicali tra le iscrizioni esametriche ed elegiache dal vII al v sec. a.C. e l'epos arcaico: I. Iscrizioni sepolcrali», QUCC 7: 45-73.

EgLI, Franziska (2003), Euripides im Kontext zeitgenössischer intellektueller Strömungen. Leipzig.

FARNell, Lewis R. (1921), Greek Hero Cults and Ideas of Inmortality. Oxford.

GeNTILI, Bruno (1968), «Epigramma ed elegia», en L'Epigramme Grecque, EntrHardt 14, Ginebra: $37-90$.

GonzÁlez GonzÁlez, Marta (2011), «Un eco de Semónides Fr. 7 en CEG II 530», ZPE 178: 26-28.

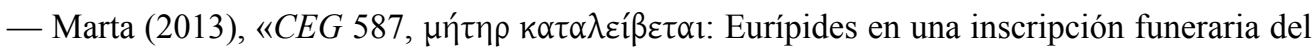
s. IV a.C.», ZPE 185: 61-62.

Guthrie, William K.C. (1950), The Greeks and their Gods. Londres.

- (1984), Historia de la filosofía griega I. Los primeros presocráticos y los pitagóricos, trad. cast. Madrid.

JiMÉNEZ, Ana Isabel (2011), «El Más Allá en inscripciones dionisíacas», en R. Martín Hernández \& S. Torallas Tovar (eds.), Conversaciones con la Muerte. Diálogos del hombre con el Más Allá desde la Antigüedad a la Edad Media. Madrid: 67-94.

Johnston, Sarah Iles (1999), Restless Dead: Encounters between the Living and the Dead in Ancient Greece. Berkeley \& Los Angeles.

LE BRIs, Anne (2001), La mort et les conceptions de l'Au-Delà en Grèce ancienne à travers les épigrammes funéraires. París.

MinAi, Adrian (2010), «Soul's Aitherial Abode According to the Poteidaia Epitaph and the Presocratic Philosophers», Numen 57: 553-582

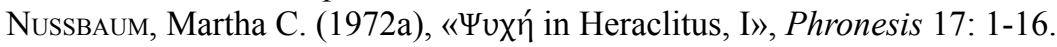

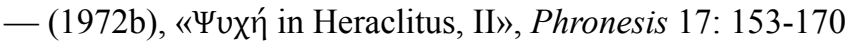

RoHde, Erwin (1948), Psique. La idea del alma y la inmortalidad entre los griegos, trad. cast. México-Buenos Aires.

RudHARDT, Jean (1992), Notions fondamentales de la pensée religieuse et actes constitutifs du culte dans la Grèce classique. París.

SAssi, Maria Michela (1981), «Riflessione filosofica e ideologia funeraria: la stele di Aristocle», DialArch 1: 33-40.

Sourvinou-Inwood, Christiane (1955), 'Reading' Greek Death to the End of the Classical Period. Oxford.

Vegetti, Mario (1989), L'etica degli antichi. Bari.

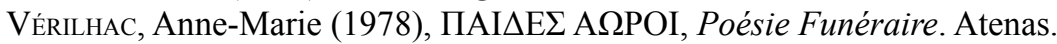

VernANT, Jean-Pierre (1974), «Le mythe prométhéen chez Hésiode», en Mythe et société en Grèce ancienne. París: 177-194. 